\title{
FATIGUE RESISTANCE OF ASPHALT CONCRETE PAVEMENTS. PECULIARITY AND ASSESSMENTS OF POTENTIALS
}

\author{
Zhongyu Li ${ }^{1}$, Tingguo Liu $^{2}$, Jicun Shi ${ }^{3}$, Uladzimir Veranko ${ }^{4}$, Vitali Zankavich ${ }^{5}$ \\ ${ }^{1,2}$ Henan Gaoyuan Highway Maintenance Technology Co., Ltd, Gaoyuan Rd., 6, Xinxiang 453003, China \\ ${ }_{1,2}$ National Engineering Laboratory for Highway Maintenance Equipment, Gaoyuan Rd., 6, Xinxiang 453003, China \\ $3,4,{ }^{5}$ Henan Provincial Key Laboratory of Highway Detection and Maintenance Technologies, \\ Gaoyuan Rd., 6, Xinxiang, 453003, China \\ E-mail: ${ }^{1}$ lizhongyu@chngaoyuan.com; ${ }^{2}$ liutingguo@chngaoyuan.com; ${ }^{3}$ shijicun@chngaoyuan.com; \\ ${ }^{4}$ uladzimirveranko@chngaoyuan.com; ${ }^{5}$ vitali.zankavich@chngaoyuan.com
}

\begin{abstract}
This article presents the results of research of processes of deformation and destruction of asphalt concrete pavements under cyclic loads. As the ground for such approach to estimation of the asphalt concrete properties served the proof that regardless of the composition and structure of asphalt concrete with an equal amount of elastic (viscoplastic) bonds possess the same relaxation ability. This situation is a significant feature of the behaviour of asphalt concrete, which opens the way for the development of certain approaches to the analysis of their properties, evaluation of reliability and durability. The promising methodology for the comparative assessment of fatigue and cyclic durability of asphalt concrete by exploring the complex set of elastic and viscoplastic bonds in their structure depending on the temperature, magnitude, and modes of action of the loads is proposed in the presented work. In the future, the establishment of patterns of behaviour of asphalt concretes with the same set of elastic bonds is allows to optimize compositions based on the principles of temperature-structural analogythat is relevant in studying fatigue and cyclic durability as well as low-temperature crack resistance and shear stability.
\end{abstract}

Keywords: asphalt concrete, cyclic life, elastic bonds, energy of rupture, fatigue, strain, stress, toughness, viscoelasticity.

\section{Introduction}

Fatigue life of asphalt concrete is one of the most important criteria, ensuring reliable and durable work of the road structures, particularly subjected to repeated loads under a wide temperature-time range. When choosing the type of asphalt concretes for road pavements it is decisive to have a methodology for comparative evaluation of their fatigue properties.

Material fatigue is the accumulation of damageability due to the impact of variable (cyclic) loadings, resulting in its destruction over a specified period.

In world practice there are many types of tests with subsequent definitions of the fatigue properties under constant value of stress or deformation (Kennedy 1977; Maggiore et al. 2014; Pell, Cooper 1975; Picado-Santos et al. 2009; Pronk 2009; Raithby, Sterling 1972; Van Dijk 1975), for example:

- 2-point bending;

- 3-point bending;

- 4-point bending;

- torsional bending;
- direct test with axial loading (tension/compression, tension);

- split test (indirect tensile test).

All of these test methods have both advantages and disadvantages from assessing the asphalt concrete resist to cyclic stress as part of road constructions (Di Benedetto et al. 2004; Li et al. 2015; Molenaar 2007). There are numerous methodologies of asphalt concrete fatigue evaluation (Cao et al. 2016; Carpenter, Jansen 1997; Dondi et al. 2013; Finn et al. 1977; Georgouli et al. 2016; Griffith 1921; Irwin 1977; Kim, Buttlar 2009; Kim, Little 1990; Lucas et al. 2016; Pronk, Hopman 1991; Roque et al. 1999; Walubita et al. 2005; Yuan et al. 2013), for example:

- methodologies based on the study of stress and strain;

- distortion energy methodologies;

- methodologies based on fracture mechanics.

At the same time unambiguous solution of the problem of the rate setting and the asphalt concrete pavements fatigue assessment is still lacking due to the complicated correlation between appropriate deformations 
development and the real road structures. A long experiment is required and result depends on numerous factors, determining the impact of transport, climate, particularities of construction (repairs) technology. Results of the fatigue life calculations often differ by tens and hundreds of times. In most cases, the necessary long-term testing is required, and that hampers operational quality control of the asphalt concrete, for example, in a production environment and requires expensive equipment. Thus, the unification of criterion and its use for the rate setting indicators of the asphalt concrete properties in the technical specifications is hampered. Very often it is difficult to use the tests results for the practical purposes of designing and calculation of road pavements the criteria of the fatigue life is major factor in the assessment of the reliability of the asphalt concrete in the design of the road constructions and requires constant improvement.

\section{Peculiarity and prospects for the assessment of the asphalt concrete fatigue life}

Complexity of asphalt concrete fatigue life evaluation lies in the fact it combines the properties of coagulation, condensation, and crystallization structures. In such systems the location of the various bounds, the binder matrix and the secondary structure of the uneven volume distribution of material, the strength and stress-related characteristics of structural units and clusters are also highly heterogeneous. From the point of view of deformation and fracture mechanics, the structure of such materials is represented in the form of a phenomenological model with a complex set of elastic, viscous and plastic bounds, alternating series and parallel patterns (Fig. 1).

Each model bound (elastic, viscous, plastic) has its own mechanical characteristics, resulting in asphalt concrete range of elastic-viscose-plastic properties. Variation of temperature, load and/or mode of loading causes replacement of some bounds (e.g. elastic by viscous).

Depending on temperature, mode of loading, the composition of asphalt concrete, the process of forming involves different numbers of elastic and viscoplastic bounds. Accordingly, the asphalt concrete exhibits varying degrees of elastic or viscous properties.

In case if only elastic bounds are deformed, full reversibility of the deformation is observed; failure occurs according to the brittle mechanism without influence of load action duration. Conversely, viscose-plastic bounds are responsible for residual strains, which are affected by temperature and loading time.

The accumulation of damage in the structure of asphalt concrete occurs in two ways:

- breaking of elastic bonds;

- achieving limit deformation of viscoplastic bounds.

Regardless of the composition and structure, asphalt concrete with an equal amount of elastic (viscoplastic) bounds has the same relaxation ability, relaxation rate, ratio of the transverse deformation and balance between the amounts of dissipated and stored energy. The reason is that with the same amount of bounds, relaxation rate inhibition causes a decrease of the relaxation constants by the same amount. This situation is the valued feature of the studied materials behaviour, which allows developing some approaches to their properties analysis, of such as fatigue life.

In the development of methodological grounds of assessment of the reliability and durability of asphalt concrete structural layers of road pavements in Henan province (China) the research was based on the fact that accumulation of damageability in the asphalt concrete structure caused by cyclic actions would be determined by the following factors:

- amount of elastic bounds involved in the process of deformation;

- maximum asphalt concrete strength in the whole range of temperature (load action duration);

- maximal deformation in the whole range of temperature (load action duration).

In case if to denote the proportion of elastic bounds responsible for the asphalt concrete condition by some scalar $n_{r}$ and viscoplastic by $n_{v}$, then meets the following condition Eq (1) (the subject is still missing):

$$
n_{r}+n_{v}=1
$$

Since as the result of viscoplastic bounds deformation complete dissipation of applied energy occurs, it is theoretically possible to accept that the ratio $n_{r}$ is $n_{v}$ determined by the ratio of the dissipative energy to the applied energy. In this case, the number $n_{r}$ and $n_{v}$ depends ultimately on the relaxation properties of the asphalt concrete and the time of load action; the number of elastic bounds involved in the deformation process determined from the following dependencies Eq (2):

$$
n_{r}=\frac{E_{t}}{E_{c}}=\left(\frac{R_{t}}{R_{c}}\right)^{\frac{1}{m}} \text {, }
$$

where $E_{t}$ and $R_{t}$ - relaxation modulus and strength of asphalt concrete under specific conditions of load and temperature, $\mathrm{MPa} ; E_{c}$ and $R_{c}$ - maximum values of the relaxation modulus and strength throughout the whole temperature and speed (time) of load action range, MPa; $m$ - coefficient depending on the properties (type) of asphalt concrete.

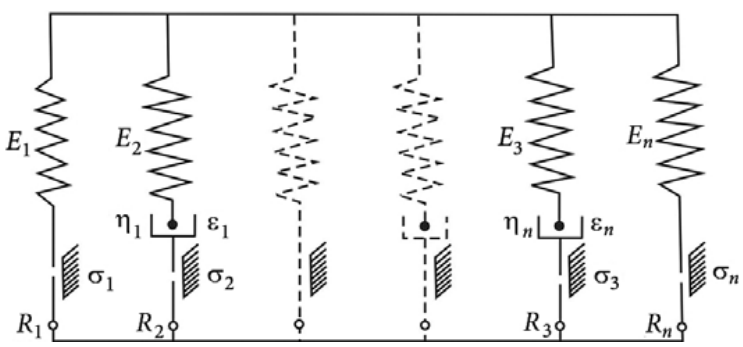

Fig. 1. Phenomenological model of asphalt concrete 
The value of the coefficient $m$ for asphalt concrete is in the range of $0.75-0.90$ and determined first by its modulus of elasticity (stiffness). The higher the modulus of elasticity (stiffness), the higher the ratio $m$, and for simply calculations is equal to 0.8 .

The value $n_{r}$ changes in the process of creeping and relaxation as a function of $E_{t}$ stress and load action time and causes the complex influence on the properties of asphalt concrete, and the mechanics of its destruction.

The Boltzmann-Volterra equation is presented in the next form for the core $T(\tau)$ that determines the stress relaxation process Eq (3)-(4):

$$
\begin{aligned}
& \frac{\sigma_{t}}{\sigma_{0}}=1-\int_{0}^{t} T(\tau) d \tau, \\
& \frac{E_{t}}{E_{0}}=1-\int_{0}^{t} T(\tau) d \tau,
\end{aligned}
$$

where $\sigma_{0}, E_{0}$ - stress and relaxation module in the initial moment of the loading time action, MPa; $\sigma_{t}, E_{t}-$ stress and relaxation module in the moment $t$ of the loading time action, MPa.

For the asphalt concretes with the same relaxation cores $T(\tau)$ condition Eq (5):

$$
\frac{E_{t_{1}}}{E_{0_{1}}}=\frac{E_{t_{2}}}{E_{0_{2}}},
$$

automatically ensures the fulfilment of the condition Eq (6):

$$
\frac{\sigma_{t_{1}}}{\sigma_{0_{1}}}=\frac{\sigma_{t_{2}}}{\sigma_{0_{2}}} .
$$

In fact, if the two different properties of asphalt concrete (for example, maximum relaxation modulus $E_{c}$ ) with

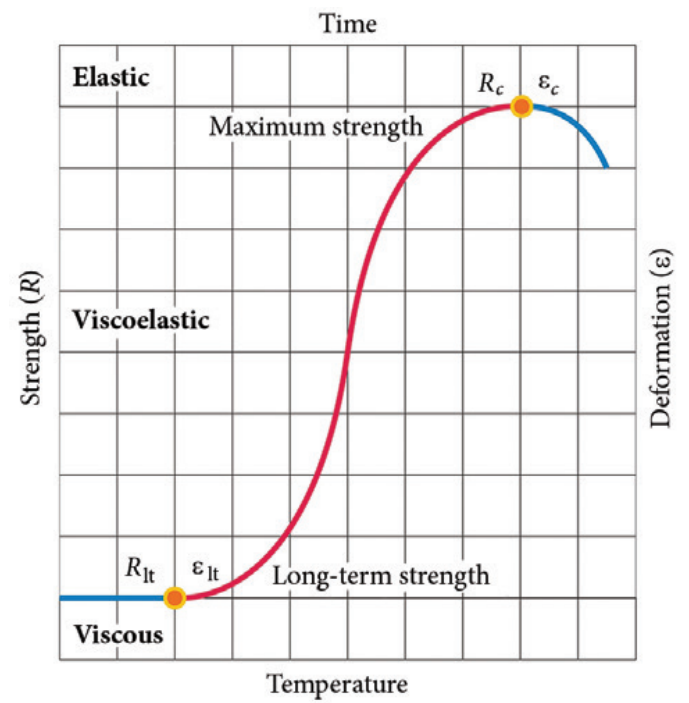

Fig.2. Characteristics of asphalt concrete depending on the temperature (time of loading) equal $n_{r}$ (with equal relaxation ability) are subjected to an instantaneous strain $\varepsilon$, the stress values in each of them are (Eq (7)):

$$
\sigma_{0_{1}}=\varepsilon E_{c_{1}}, \quad \sigma_{0_{2}}=\varepsilon E_{c_{2}} .
$$

After a certain period $t$ the stress in each asphalt concrete reaches the level Eq (8):

$$
\sigma_{t_{1}}=\varepsilon E_{t_{1}}, \sigma_{t_{2}}=\varepsilon E_{t_{2}} .
$$

Accepting as the factor of relaxation ability rations of initial stress to the current one, get $\mathrm{Eq}$ (9):

$$
\frac{\sigma_{t_{1}}}{\sigma_{0_{1}}}=\frac{E_{t_{1}}}{E_{0_{1}}}, \frac{\sigma_{t_{2}}}{\sigma_{0_{2}}}=\frac{E_{t_{2}}}{E_{0_{2}}} .
$$

Hence, the equality of the right sides of expressions $\mathrm{Eq}(5)$ and, consequently, the equality of the stress ratio, theoretically confirms the proposition about equal relaxation ability of materials with the same $n_{r}$.

When the asphalt concrete works in the elastic mode $\left(n_{r} \rightarrow 1\right)$, its strength $R_{c}$ is equal to the maximum in the whole temperature range (load action time). Since the number of cycles to fracture depends on the ratio of stresses to strength, then the higher $R_{c}$, the higher is the cyclic stability of asphalt concrete in elastic work stage, and the higher level of the damage in the material is achieved at the time of destruction. Therefore, the value $R_{c}$ serves as a criterion of cyclic durability under constant stress in the elastic work stage (Fig. 2).

The maximum strength of asphalt concrete in the entire temperature range (duration of load) is calculated by the split test results (indirect strain) of standard cylindrical samples according to the following dependencies Eq (10):

$$
R_{c}=\frac{\frac{R_{t_{1}}^{T}+R_{t_{2}}^{T}}{2}}{1+k_{1} \log \left(\frac{R_{t_{1}}^{T}}{R_{t_{2}}^{T}}\right)},
$$

where $R_{t_{1}}^{T}$ - the strength of asphalt concrete at a rate of load action $t_{1}$ and test temperature $T, \mathrm{MPa} ; R_{t_{2}}^{T}$ - the strength of asphalt concrete at a rate of load action $t_{2}$ and test temperature $T, \mathrm{MPa} ; k_{1}$ - coefficient depending on the test conditions (rate of load action, temperature).

For example, the value of the coefficient $k_{1}$ is:

- for temperature $-10{ }^{\circ} \mathrm{C}$, for the rate of load action $t_{1}=1 \mathrm{~mm} / \mathrm{min}$ and $t_{2}=10 \mathrm{~mm} / \mathrm{min}-$ is 2.64 ;

- for temperature $-15{ }^{\circ} \mathrm{C}$, for the rate of load action $t_{1}=3 \mathrm{~mm} / \mathrm{min}$ and $t_{2}=10 \mathrm{~mm} / \mathrm{min}-$ is 1.92 .

Figure 3 presents the data, correlating experimental results with the results of calculation $R_{c}$ by formula (10) for the coefficient values $k_{1}=2.64$, obtained for asphalt concrete structural layers of road pavements in Henan province (China). 
In China and Belarus to assess the ability of asphalt concrete to resist the fatigue strain. an indicator of their maximum strength in the entire temperature range (duration of load) $R_{c}$ is used, because regardless of the asphalt concrete work schemes in a road construction. the fatigue build-up is determined by rupture and damage to elastic bounds. Also, the value $R_{c}$ reflects the potential of the asphalt concrete to resist the fatigue deformation show and damage caused by cyclic loads but needs refinement as a characteristic uniquely determining the fatigue life when used in road construction.

In case if loading regime corresponds to the asphalt concrete work in a viscous stage $\left(n_{r} \rightarrow 0\right)$, then the longer cyclic fatigue life demonstrates the asphalt concrete capable of dispersing a greater amount of energy before destruction $W_{d}$, which is correlated with the maximum deformation $\varepsilon_{m}$, in a wide range of temperature and the load action duration. Asphalt concrete performance in a viscous state is observed in the course of relaxation processes, creep.

Since the increase of $R_{c}$ enhancing the likelihood of increased fatigue life in the elastic work stage and the increase of $\varepsilon_{m}$ in the viscous stage, in general case $\left(0<n_{r}<1\right)$ the materials with the maximum value of $R_{c} \varepsilon_{m}$ are maximum fatigue cyclic life.

Figures 4-5 presents the analytical processing of definition dependence of the cycles number limit of rapture at constant acting stresses and deformations from the estimated traffic load, defined by finite element method applied to three-layer pavement. Asphalt concrete under investigation was specified as stone matrix asphalt. From the dependences described herein, it follows that the increase in cycles number up to fracture under continues stress with increasing values of maximum asphalt concrete strength $R_{c}$ is definite.

The situation is somewhat different when the material is subjected to continuous strain level (Fig. 5). In this case, the dependence of a maximum number of cycles until rapture $n_{r}$ would be presented by the extreme curve, because under continuous strain, stress increases with the increase of $n_{r}$, due to the increased module $E_{t}=f\left(n_{r} \cdot E_{c}\right)$. Therefore, the higher $n_{r}$, the fewer cycles elastic bounds survive before the rapture. Conversely, viscoplastic bounds $n_{v}$ with $n_{r}$ increase carry a smaller portion of the total deformation and their fatigue life increases.

As a result, maximum material durability is observed at defined optimal ratio of the elastic and viscoplastic bounds.

Figure 6 presents dependence of determining the maximum number of cycles to rapture (cyclic durability) under the estimated traffic load of $130 \mathrm{kN}$.

As Fig. 6 shows, the asphalt concretes with a high value of maximum strength $R_{c}$ have a higher potential to resist cyclic stresses. At the same time for such asphalt concrete, it is essential to control some elastic deformation bounds $n_{r}$ involved under the appropriate temperature, load and loading conditions.

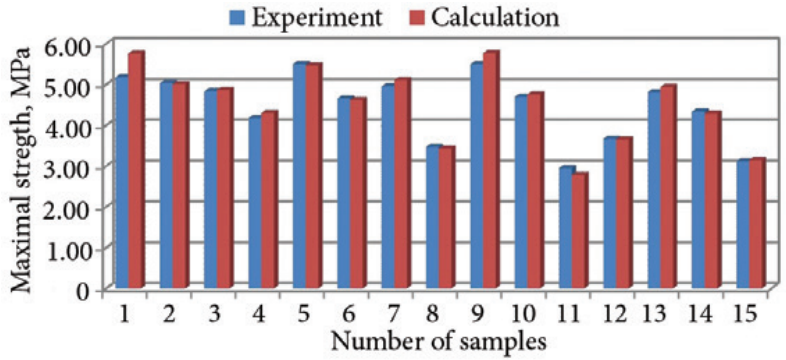

Fig. 3. Results of experimental and calculated definition data comparison $R_{c}$

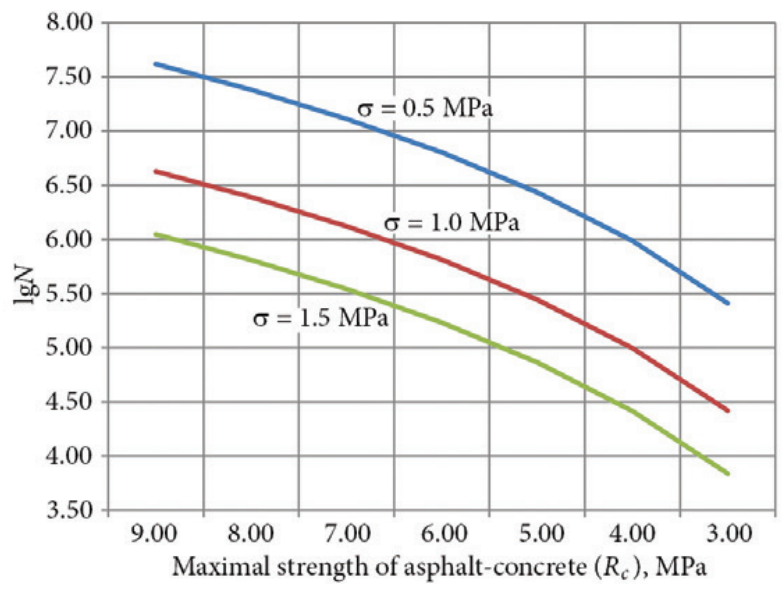

Fig. 4. Durability of asphalt concrete under cyclic continues stress

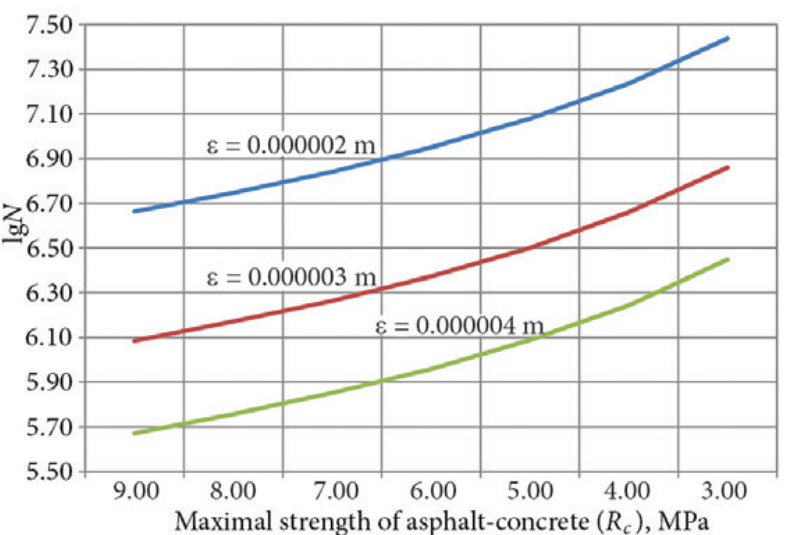

Fig. 5. Durability of asphalt concrete under cyclic continues deformations

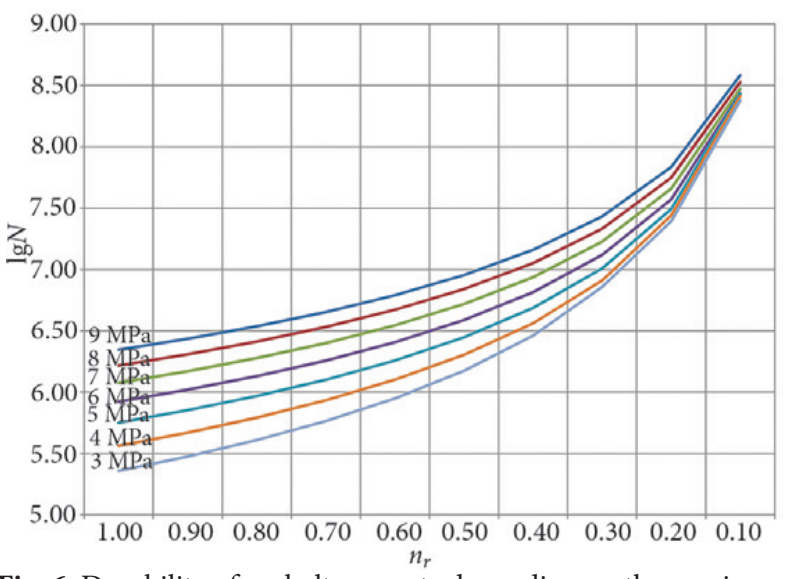

Fig. 6. Durability of asphalt concrete depending on the maximum strength and the amount elastic bounds, involved in the deformation process 
The analysis of theoretical and practical results of the research proved that as a criterion for determining fatigue life of asphalt concrete, besides their maximum strength, is the number of elastic bounds $n_{r}$ involved in the process of deformation. The tests were carried out under the following conditions: at a temperature of $0{ }^{\circ} \mathrm{C}$ (Belarus) or $15^{\circ} \mathrm{C}$ (Chi$\mathrm{na}$, Henan Province) and the strain rate of $50 \mathrm{~mm} / \mathrm{min}$.

The maximum strength $R_{c}$ of $6 \mathrm{MPa}$ to $9 \mathrm{MPa}$ and above is attainable mainly for asphalt concrete modified with polymers, from $3 \mathrm{MPa}$ to $6 \mathrm{MPa}$ for asphalt concrete on clean road bitumen. Some elastic bounds $n_{r}$ at rated conditions for modified asphalt concrete used for paving on motorways of high technical categories is in the range of less than $0.55-0.85$, of asphalt concrete on the pure bitumen - less than 0.40-0.55.

Thus, a rather simple and reliable way is presented for the optimization of the asphalt mixtures properties at the stage of mix design by the criteria of the fatigue and cyclic durability.

\section{Conclusions}

1. This article presents the results of a study of the asphalt concrete ability to resist the cyclic stress caused by transport.

2. It is established that the value of asphalt concretes maximum (structural) strength in the whole temperature range and modes of load action is suitable for their assessment of asphalt concrete ability to withstand the accumulation of fatigue leading to destruction.

3. Theoretically, confirmed prerequisites to the facts that asphalt concretes having the optimum ratio of the elastic and viscoplastic bounds ensure maximum cyclelife under the temperature range and the load modes. The less material brittle, the less its elastic bounds work, less the likelihood of fatigue deformation, ceteris paribus.

4. The maximum strength of $6 \mathrm{MPa}$ to $9 \mathrm{MPa}$ and above is attainable mainly for asphalt concrete modified with polymers, from $3 \mathrm{MPa}$ to $6 \mathrm{MPa}$ for asphalt concrete on road bitumen. Some elastic bounds at rated conditions for modified asphalt concrete used for paving on motorways of high technical categories are in the range of less than $0.55-0.85$, for asphalt concrete on the pure bitumen - less than $0.40-0.55$.

5. The direction for future research, associated with the implementation of complex experimental and theoretical studies, is set. This methodology for assessing the reliability and durability of asphalt concrete pavements under cyclical impact of transportation and climatic factors during the service life is urgent for optimizing the process of asphalt concretes mix design.

\section{Acknowledgments}

This study is part of a large-scale projects founded by the Major Project of Henan Province Science and Technology Department (Grant No. 151100310600), National Key Technology Research and Development Program of the Ministry of Science and Technology of China (Grant
No. 2015BAF07B08) and Inter-Governmental Cooperation on International Science and Technology Innovation of the Ministry of Science and Technology of China (Grant No. 2016YFE0111000). The contents of this paper reflect the views of the authors, who are responsible for the facts and the accuracy of the data presented herein.

\section{References}

Cao, W.; Norouzi, A.; Kim, R. 2016. Application of Viscoelastic Continuum Damage Approach to Predict Fatigue Performance of Binzhou Perpetual Pavements, Journal of Traffic and Transportation Engineering (English Edition) 3(2): 104-115. https://doi.org/10.1016/j.jtte.2016.03.002

Carpenter, S. H.; Jansen, M. 1997. Fatigue Behaviour under New Aircraft Loading Conditions, in Proc. Aircraft/Pavement Technology: in the Midst of Change: selected papers. Ed. by Hermann, F. V. 17-20 August Seattle, USA. New York: American Society of Civil Engineers, 259-271.

Di Benedetto, H.; de la Roche, C.; Baaj, H.; Pronk, A.; Lundstrom, R. 2004. Fatigue of Bituminous Mixtures, Materials and Structures 37(3): 202-216. https://doi.org/10.1007/BF02481620

Dondi, G.; Pettinari, M.; Sangiorgi, C.; Zoorob, S. E. 2013. Traditional and Dissipated Energy Approaches to Compare the $2 \mathrm{~PB}$ and $4 \mathrm{~PB}$ Flexural Methodologies on a Warm Mix Asphalt, Construction and Building Materials 47: 833-839. https://doi.org/10.1016/j.conbuildmat.2013.05.091

Finn, F.; Saraf, C.; Kulkarni, R.; Nair, K.; Smith, W.; Abdullah, A. 1977. The Use of Distress Prediction Subsystems for the Design of Pavement Structures, in Proc. of the $4^{\text {th }}$ International Conference on the Structural Design of Asphalt Pavements: selected papers, vol. 1. 22-26 August 1977, Ann Arbor, USA. Ann Arbor: University of Michigan, 3-38.

Georgouli, K.; Plati, C.; Loizos, A. 2016. The Impact of Dynamic Modulus of Various HMA Mixes on Fatigue Cracking Prediction, in Proc. $4^{\text {th }}$ Chinese-European Workshop on Functional Pavement Design (4 $4^{\text {th }}$ CEW 2016), 29 June - 01 July 2016, Delft, Netherlands. CRC Press. p. 221

Griffith, A. A. 1921. The Phenomena of Rupture and Flow in Solids, Philosophical Transactions of the Royal Society of London. Series A, Papers of a Mathematical or Physical Character 221: 163-198. https://doi.org/10.1098/rsta.1921.0006

Irwin, L. H. 1977. Use of Fracture Energy as a Fatigue Failure Criterion, in Proc. of Association of Asphalt Paving Technologists Proc 46: 41-63.

Kennedy, T. W. 1977. Characterization of Asphalt Pavement Materials Using the Indirect Tensile Test, in Proc. of Association of Asphalt Paving Technologists Proc 46: 132-150.

Kim, H.; Buttlar, W. G. 2009. Discrete Fracture Modeling of Asphalt Concrete, International Journal of Solids and Structures 46(13): 2593-2604. https://doi.org/10.1016/j.ijsolstr.2009.02.006

Kim, Y. R.; Little, D. N. 1990. One-Dimensional Constitutive Modelling of Asphalt Concrete, Journal of Engineering Mechanics 116(4): 751-772.

https://doi.org/10.1061/(ASCE)0733-9399(1990)116:4(751)

Lucas, F.; Soares, J. B.; Ferreira. J. L. S.; Do Nascimento, L. A. H. 2016. Evaluation of Fatigue Behavior of Aged Asphalt Mixtures Using the Simplified Viscoelastic Continuum Damage Model, in Proc. $8^{\text {th }}$ RILEM International Conference on Mech- 
anisms of Cracking and Debonding in Pavements: selected papers, vol. 13. 7-9 June, Nantes, France. Springer: Dordrecht, 9-15. https://doi.org/10.1007/978-94-024-0867-6_2

Li, N.; Molenaar, A. A. A.; Pronk, A. C.; Van de Ven, M. F. C.; Wu, S. 2015. Application of the Partial Healing Model on Laboratory Fatigue Results of Asphalt Mixture, Construction and Building Materials 95: 842-849.

https://doi.org/10.1016/j.conbuildmat.2015.07.127

Maggiore, C.; Airey, G.; Marsac, P. 2014. A Dissipated Energy Comparison to Evaluate Fatigue Resistance Using 2-Point Bending, Journal of Traffic and Transportation Engineering (English Edition) 1(1): 49-54. https://doi.org/10.1016/S2095-7564(15)30088-X

Molenaar, A. A. A. 2007. Prediction of Fatigue Cracking in Asphalt Pavements: Do We Follow the Right Approach?, Transportation Research Record 2001: 155-162.

https://doi.org/10.3141/2001-17

Pell, P. S.; Cooper, K. E. 1975. The Effect of Testing and Mix Variables on the Fatigue Performance of Bituminous Materials, Journal of the Association of Asphalt Paving Technologists 44: 1-37.

Picado-Santos, L.; Almeida, A.; Pais, J.; de Lurdes Antunes, M.; Batista, F. 2009. Assessment of Stiffness and Fatigue Tests in Portugal, in Proc. of the $2^{\text {nd }}$ Workshop on Four Point Bending: selected papers. Ed. by Paes, J. 24-25 September 2009, Guimaraes, Portugal. Guimaraes: University of Minho, 105-112.

Pronk, A. C. 2009. Fatigue Life NPH in 4PB Tests: A Proposal, in Proc. of the $2^{\text {nd }}$ Workshop on Four Point Bending: selected papers. Ed. by Paes, J. 24-25 September 2009, Guimaraes, Portugal. Guimaraes: University of Minho, 7-18.
Pronk, A. C.; Hopman, P. C. 1991. Energy Dissipation: the Leading Factor of Fatigue, in Proc. of the International Conference "The United States Strategic Highway Research Program (SHRP): Sharing the Benefits": selected papers. 29-31 October, London, United Kingdom. London: Telford, 255-267.

Raithby, K. D.; Sterling, A. B. 1972. Some Effects of Loading History on the Performance of Rolled Asphalt. TRRL Report LR 496. Crowthorne: Transport and Road Research Laboratory. 18 p.

Roque, R.; Zhang, Z; Sankar, B. 1999. Determination of Crack Growth Rate Parameters of Asphalt Mixtures Using the Superpave IDT, in Proc. of Association of Asphalt Paving Technologists Proc 68: 404-433.

Van Dijk, W. 1975. Practical Fatigue Characterization of Bituminous Mixes, Journal of the Association of Asphalt Paving Technologists 44: 38-72.

Walubita, L. F.; Martin, A. E.; Jung, S. H.; Glover, C. J.; Chowdhury, A.; Park, E. S.; Lytton, R. L. 2005. Preliminary Fatigue Analysis of a Common TxDOT Hot Mix Asphalt Concrete Mixture. Technical Report № FHWA/TX-05/0-4468-1. Austin: Texas Dept of Transportation. $142 \mathrm{p}$.

Yuan, M. M.; Zhang, X. N.; Chen, W. Q.; Zhang, S. X. 2013. Ratio of Dissipated Energy Change-Based Failure Criteria of Asphalt Mixtures, Research Journal of Applied Sciences, Engineering and Technology 6(14): 2514-2519.

Received 24 November 2016; accepted 09 September 2017 